\title{
Lower Plasma Ghrelin Levels are Found in Women with Diabetes- Complicated Pregnancies
}

\author{
Rita Angélica Gómez-Díaz1, Monica P. Gómez-Medina2, Eleazar Ramírez-Soriano3, \\ Lucio López-Robles2, Carlos A. Aguilar-Salinas4, Renata Saucedo5, Arturo Zarate5, \\ Adan Valladares-Salgado6, Niels H. Wacher1
}

\author{
${ }^{1}$ National Medical Center "Siglo XXI", Mexican Social Security Institute, UMAE Hospital of Specialties, Unit of Medical Research in Clinical \\ Epidemiology, Mexico City, Mexico \\ 2UMAE Hospital of Specialties, Clinic of Obstetrics Gynecology, Mexico City, Mexico \\ 3National Medical Center "La Raza", Hospital of Gynecology Pediatrics 3A, Mexico City, Mexico \\ ${ }^{4}$ National Institute of Medical Sciences and Nutrition, Department of Endocrinology and Metabolism, Mexico City, Mexico \\ ${ }_{5}^{5}$ National Medical Center "Siglo XXI", Mexican Social Security Institute, UMAE Hospital of Specialties, Unit of Medical Research in \\ Endocrine Diseases, Mexico City, Mexico
}

${ }^{6}$ National Medical Center "Siglo XXI", Mexican Social Security Institute, UMAE Hospital of Specialties, Unit of Biochemistry, Mexico City, Mexico

\section{WHAT IS ALREADY KNOWN ON THIS TOPIC?}

Although ghrelin and proinsulin can regulate several metabolic pathways, few studies have evaluated these hormones in mothers with diabetes and their neonates.

\section{WHAT THIS STUDY ADDS?}

Our results indicate that pregnant women with gestational or type 2 diabetes had significantly lower ghrelin levels, compared to non-diabetic pregnant women. However, pregnant women with gestational diabetes had significantly lower proinsulin levels, compared to non-diabetic pregnant women. Thus, ghrelin participates in the adaptation to the caloric imbalance of diabetic pregnancy and may play a similar role in pregnancyrelated complications, since high ghrelin concentrations may be necessary for normal fetal development.

\section{ABSTRACT}

Objective: To evaluate the associations of glycemic control and gestational age with ghrelin and proinsulin levels in cord blood and mothers' peripheral blood during pregnancy.

Methods: This is a cross-sectional comparative study of twenty-four pregnant women with gestational diabetes (GD), 18 with type 2 diabetes mellitus (T2DM), and 36 without diabetes, as well as their neonates. Levels of proinsulin, ghrelin, and glycated hemoglobin $\mathrm{A} 1 \mathrm{c}(\mathrm{HbA1c})$ were measured from maternal blood during the last week before caesarian delivery and in neonatal umbilical cord blood samples.

Results: Mothers with GD and T2DM had significantly lower ghrelin levels compared to the healthy mothers $(p<0.001)$. Maternal proinsulin was lower in women with GD than in women without diabetes $(p<0.001)$. Proinsulin was significantly elevated in the neonates of women with $\mathrm{GD}$ and in women with $\mathrm{HbA1c} \geq 6.5 \%(p<0.001)$. However, maternal ghrelin levels were higher $(\mathrm{p}=0.031)$ and neonate proinsulin levels lower in the pre-term offspring of mothers with $\mathrm{GD}(\mathrm{p}=0.033)$. There was a negative correlation between $\mathrm{HbA1}$ c levels and birth weight $(r=-0.407, p<0.001)$.

Conclusion: Ghrelin levels were lower in pregnant women with diabetes, although pre-term birth appeared to reverse this trend in GD. Proinsulin levels were also low in pregnant women with diabetes and even lower in pre-term vs. at-term births. Both ghrelin and proinsulin levels were lower in pregnant women with diabetes and HbA1C of $<6.5 \%$. Thus, ghrelin participates in the adaptation to the caloric imbalance of diabetic pregnancy and may play a similar role in pregnancy-related complications, since high ghrelin concentrations may be necessary for normal fetal development.

Keywords: Proinsulin, ghrelin, diabetes, hyperglycemia, neonates

Conflict of interest: None declared

Received: 14.10 .2015

Accepted: 19.07 .2016

Address for Correspondence

Rita Angélica Gómez-Díaz MD, National Medical Center "Siglo XXI", Mexican Social Security Institute, UMAE Hospital of Specialties, Unit of Medical Research in Clinical Epidemiology, Mexico City, Mexico Phone: +52-55-5627-6900 ext. 21481, 21507 E-mail: ritagomezdiaz@yahoo.com.mx O Journal of Clinical Research in Pediatric Endocrinology, Published by Galenos Publishing. 
Gómez-Díaz RA et al.

Glycemic Control, Ghrelin and Proinsulin

\section{Introduction}

Ghrelin helps modulate appetite and regulate several metabolic pathways. This peptide hormone is mainly produced in the stomach, although small amounts are also produced in the hypothalamus, kidney, heart, pancreatic cells, and placenta (1). Ghrelin has a role in both endocrine (e.g., the release of prolactin and adrenocorticotrophic hormone) and non-endocrine (e.g., stimulating gastric acid secretion and intestinal motility) functions $(2,3)$. Ghrelin has two molecular forms: acylated ghrelin (acylated at the serine-3 residue) and des-acyl ghrelin. Women with gestational diabetes (GD) have lower levels of acylated ghrelin, which may reflect the inhibitory effect of insulin on ghrelin secretion (4). Although the role of ghrelin in fetal adaptation to intrauterine malnutrition is incompletely understood, there are studies which indicate a strong correlation between acylated and total ghrelin levels as a parameter for neonatal ghrelin regulation $(5,6,7)$. Nevertheless, high ghrelin concentrations appear to be necessary for normal fetal development and this requires an optimal uterine environment that is free from hyperglycemia (8).

The relationships between ghrelin levels and various anthropometric and biochemical measurements remain controversial (9). Diabetes may also affect ghrelin concentrations, as plasma ghrelin levels are thought to decrease during hyperglycemia and hyperinsulinemia, although studies of ghrelin levels in pregnant women with diabetes are scarce (10).

Proinsulin is synthesized by the early embryo, before the differentiation of the pancreas. Proinsulin stimulates cardiogenesis and prevents apoptosis during neurulation (11). As sugars easily cross the placenta, the fetal pancreas responds to hyperglycemia by increasing insulin production. This process leads to fetal hyperinsulinemia, which affects carbohydrate, protein, and fat metabolism and is associated with an increased risk of metabolic diseases in adulthood $(10,12)$. Furthermore, similar to insulin and insulin-like growth factor 1, proinsulin has an impact as a growth factor and this property may be associated with the higher incidence of congenital defects among children of diabetic mothers $(11,13,14,15,16)$. Hyperglycemia can also induce metabolic damage by causing beta cell injury (17). Although long-term follow-up studies on this issue are lacking, alterations in maternal metabolism are reported to be associated with pancreatic islet hyperplasia, changes which may have long-term consequences for the fetus (18).

In this present study, using glycated hemoglobin A1c (HbA1c) levels, we evaluated the association of glycemic control with ghrelin and proinsulin concentrations in umbilical cord blood and maternal peripheral blood. We also evaluated the associations between maternal and neonatal ghrelin and proinsulin levels in preterm and term deliveries.
Our hypothesis was that pregnant women with GD or type 2 diabetes mellitus (T2DM) would be more likely to have neonates with decreased ghrelin and increased proinsulin concentrations compared to the women without diabetes, which might be a risk factor for pre-term delivery.

\section{Methods}

This cross-sectional comparative study evaluated women with type 2 or GD and their offspring according to the American Diabetes Association criteria (19). We included 78 pregnant women and their neonates in the study. Of the women, $42(53.8 \%)$ were diabetics. A group consisting of $36(46.2 \%)$ healthy women and their offspring served as controls. The study and control groups were recruited from among consecutive pregnant women who were covered by our social security system and who had attended scheduled visits at the Hospital of Gynecology Pediatrics 3A (UMAE, National Medical Center "La Raza") over an 11-month period. The exclusion criteria for mothers were type 1 diabetes mellitus (T1DM), pregnancy complications (e.g. pre-eclampsia), arterial hypertension, chronic renal or hepatic disease, cardiac failure, arrhythmia, cardiomyopathy, receiving steroids within $24 \mathrm{~h}$ after delivery, and serious maternal or fetal complications during the birth process. Also excluded were neonates born vaginally, those with an Apgar score $<6$ at 1 minute, with a short umbilical cord (unable to take blood sample), with sepsis, or with meconium in the amniotic fluid. The study was approved by the Ethics and Research Committee of the Mexican Social Security Institute and complied with the tenets of the Declaration of Helsinki. All participants provided written informed consent.

A blood sample was obtained from each mother during the last week before caesarian delivery and after a 12-hour fast and was used to measure plasma $\mathrm{HbA} 1 \mathrm{c}$, ghrelin, and proinsulin concentrations. Immediately after birth, a $10-\mathrm{mL}$ cord blood sample was obtained for determination of total ghrelin and proinsulin concentrations. After the neonate became stable, supine body length (in millimeters, taken on a hard horizontal surface from crown to heel), unclothed weight (in grams), and cephalic perimeter (in centimeters) were measured. Gestational age was determined using the Capurro evaluation system (20). Infant weight was classified as adequate-, low-, or high-for-gestational-age according to the Lubchenco tables (21).

Whole blood $\mathrm{HbA} 1 \mathrm{c}$ levels were determined using ion exchange high-performance liquid chromatography (normal range: $4-6 \%)$. The untreated samples were stored in aliquots at $-80{ }^{\circ} \mathrm{C}$ until analysis. Total ghrelin and proinsulin concentrations were determined via radioimmunoassay using reagents from Millipore Corporation (MA, USA). The total ghrelin test has a sensitivity of $93 \mathrm{pg} / \mathrm{mL}$, with intra- 
Gómez-Díaz RA et al.

Glycemic Control, Ghrelin and Proinsulin

and inter-assay coefficients of variation ( $\mathrm{CVs}$ ) of $8.0 \%$ and $9.5 \%$, respectively. The proinsulin test has a sensitivity of 2 $\mathrm{pMol} / \mathrm{L}$ (normal fasting range: $7.9 \pm 1.5 \mathrm{pMol} / \mathrm{L}$ ) and $\mathrm{CVs}$ of $5.0 \%$ and $10.1 \%$, respectively.

\section{Definitions}

Maternal $\mathrm{HbA} 1 \mathrm{c}$ levels of $\geq 6.0 \%$ are generally considered indicative of inadequate glycemic control, according to the American Diabetes Association recommendations (19), while levels $<6.5 \%$ are considered adequate (22). Therefore, we defined maternal hyperglycemia as a plasma $\mathrm{HbA} 1 \mathrm{c}$ level of $\geq 6.5 \%$. Any infant born before the completion of 37 weeks of gestation was classified as pre-term and those born at 37-42 weeks as a term infant. The infants were defined as small-for-gestational-age if they were below the $10^{\text {th }}$ percentile for body weight, appropriate-for-gestationalage if between the 10th and 90th percentiles, and large-forgestational-age if above the 90th percentile in weight (21).

\section{Statistical Analysis}

Analysis of variance or the Kruskal-Wallis test was used to compare anthropometric values and ghrelin, proinsulin, and $\mathrm{HbA} 1 \mathrm{c}$ levels. A Pearson correlation coefficient test was used for data with a normal distribution and Spearman correlation coefficient for data with a non-normal distribution. Student's t-test was used to compare parametric variables and the Mann-Whitney $U$ test was used to compare the non-parametric variables, proinsulin levels in neonates of mothers with or without diabetes, proinsulin levels in preterm and at-term neonates, and according to metabolic control. All analyses were performed using Statistical Package for the Social Sciences software (version 15; SPSS Inc., Chicago, IL, USA). The "General Lineal Models" module was used in lineal regression to adjust for the confounding factors of body mass index (BMI), age, disease duration, and $\mathrm{HbA} 1 \mathrm{c}$ at the end of pregnancy. A p-value of $<0.05$ was considered significant.

\section{Results}

Table 1 shows the characteristics of the mothers and neonates. Among the mothers with diabetes, 57.1\% (24/42) had GD and $42.9 \%$ (18/42) had T2DM. The durations of type 2 and GD were $29.8 \pm 23.4$ months (range: 4-84 months) and $3.4 \pm 2.1$ months (range: 1-8 months), respectively. Among women with diabetes, 54.8\% (23/42) had an HbA1c value of $<6.5 \%, 19 \%$ (8/42) were of normal weight, $50 \%$ (21/42) were overweight, and $31 \%$ (13/42) were obese. Dietary management was prescribed for $52.4 \%$ (22/42) of these women, while insulin therapy was necessary for $37.5 \%$ $(n=9)$ of women with GD and for $61.1 \%$ of women with T2DM $(n=11)$. Only 8.3\% (3/36) of the non-diabetic mothers were overweight. It should be noted that one of the women without diabetes had an HbA1c of $6.2 \%$. Nevertheless, both her fasting glucose $(95 \mathrm{mg} / \mathrm{dL})$ and insulin $(12.7 \mu \mathrm{U} /$ $\mathrm{mL}$ ) levels were within normal ranges, and in the followup, she was not diagnosed as a diabetic in view of the principles suggested by Metzger et al (22).

Of infants born to mothers with type 2 or GD, $64.3 \%$ (27/42) were male and 45\% (19/42) were pre-term. Of these neonates, $4.7 \%$ (2/42) were of low-for-gestational-age birthweight, 69\% (29/42) of normal birthweight, and 26.3\% $(11 / 42)$ of high-for-gestational age birthweight. All neonates from non-diabetic mothers were born at term with normal birthweights and 55.6\% (20/36) were male.

There was a significant difference in proinsulin levels between neonates who were born to mothers with or without diabetes $(p<0.001)$ as well as between neonates from mothers with an $\mathrm{HbA} 1 \mathrm{c}$ level of $<6.5 \%$ or $\geq 6.5 \%$ $(p<0.001)$ (Table 1).

Pregnant women with gestational or T2DM had significantly lower plasma ghrelin levels compared to women without diabetes $(p<0.001)$. This difference remained significant after adjusting for BMI, age, disease duration, and $\mathrm{HbA} 1 \mathrm{c}$ levels at the end of pregnancy. Maternal ghrelin concentrations were significantly higher in women without diabetes vs. women with diabetes $(p=0.013)$. Ghrelin levels were also high in women with $\mathrm{HbA} 1 \mathrm{c}$ levels $<6.5 \%$ (vs. HbA1c of $\geq 6.5 \%)(p=0.01)$ (Table 2).

While maternal ghrelin levels were lower in the presence of diabetes, when only women with diabetes were evaluated, maternal ghrelin concentrations were higher in women who had pre-term deliveries (vs. term), and especially so in women with GD $(p=0.031)$. The same trend was observed for women with T2DM, although the differences were not statistically significant (Table 3). There was no difference in proinsulin levels between women with and without diabetes. Pregnant women with T2DM and at-term birth had significantly higher proinsulin concentrations vs. preterm birth $(p=0.027)$, although this trend was not significant in women with GD $(p=0.63)$. There was no difference in ghrelin concentrations between neonates who were born to mothers with or without diabetes. Furthermore, ghrelin levels were not modified by a maternal $\mathrm{HbA} 1 \mathrm{c}$ level $\geq 6.5 \%$ or by pre-term birth. Nevertheless, negative correlations were observed between $\mathrm{HbA} 1 \mathrm{c}$ concentration and birth weight $(r=-0.407, p<0.001)$, ghrelin concentrations and birth weight among term neonates $(r=-0.270, p=0.039)$, and between maternal ghrelin and neonatal ghrelin levels $(r=-0.328, p=0.034)$.

Neonates born to mothers with diabetes had significantly higher proinsulin levels, regardless of glycemic control [adequate glycemic control $(p<0.001)$ and inadequate glycemic control $(p=0.026)]$. Elevated proinsulin levels were observed in neonates born to women with T2DM and with an $\mathrm{HbA} 1 \mathrm{c}$ value of $<6.5 \%$ (177.6 pMol/L) and in neonates born to women with $\mathrm{GD}$ and an $\mathrm{HbA} 1 \mathrm{c}$ value of $\geq 6.5 \%$ (80.9 pMol/L) (data not shown). 
Gómez-Díaz RA et al.

Glycemic Control, Ghrelin and Proinsulin

\begin{tabular}{|c|c|c|c|c|c|}
\hline \multicolumn{6}{|c|}{ Table 1. Characteristics of the study sample } \\
\hline & & No diabetes & Gestational diabetes & Type 2 diabetes mellitus & \\
\hline & & $n=36$ & $n=24$ & $n=18$ & $\mathrm{p}$-value \\
\hline \multirow{4}{*}{ 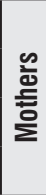 } & Age, years & $26.6 \pm 5.3(17-36)$ & $32.2 \pm 6.7(18-44)$ & $33.0 \pm 6.7(20-43)$ & $<0.001$ \\
\hline & Pre-gestational weight, $\mathrm{kg}$ & $60.6 \pm 3.4(55-67)$ & $71.6 \pm 12.4(55-107)$ & $67.4 \pm 11.9(44-96.8)$ & $<0.001$ \\
\hline & Height, $\mathrm{m}$ & $1.62 \pm 2.6(158-168)$ & $1.57 \pm 6.2(145-169)$ & $1.55 \pm 0.7(145-170)$ & $<0.001$ \\
\hline & $\mathrm{BMI}, \mathrm{kg} / \mathrm{m}^{2}$ & $22.9 \pm 1.2(20.9-25.5)$ & $28.8 \pm 4.5(22.4-40.7)$ & $27.8 \pm 4.4(20.0-41.3)$ & $<0.001$ \\
\hline \multirow{5}{*}{ 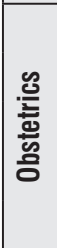 } & Previous macrosomic pregnancy, $\mathrm{n}(\%)$ & 0 & $9(37.5)$ & $1(5.6)$ & $<0.001$ \\
\hline & Previous GD, $\mathrm{n}(\%)$ & 0 & $2(8.3)$ & $1(5.6)$ & 0.240 \\
\hline & Previous congenital malformations, $\mathrm{n}(\%)$ & 0 & $3(12.5)$ & $3(16.7)$ & 0.058 \\
\hline & Pulmonary maturity inducers, $\mathrm{n}(\%)$ & 0 & $2(8.3)$ & $1(5.6)$ & 0.240 \\
\hline & Cord around the neck, $n(\%)$ & 0 & $2(8.3)$ & $4(22.2)$ & 0.016 \\
\hline \multirow{6}{*}{ 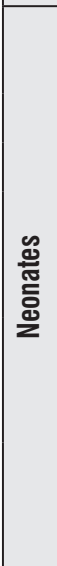 } & Weight, kg & $\begin{array}{l}3.440 \pm 0.509 \\
(3.000-3.985)\end{array}$ & \begin{tabular}{|l|}
$3.127 \pm 0.697$ \\
$(1.720-4.630)$
\end{tabular} & \begin{tabular}{|l|}
$3.268 \pm 0.527$ \\
$(2.380-4.060)$
\end{tabular} & 0.110 \\
\hline & Height, $\mathrm{cm}$ & $50.11 \pm 0.62$ (49-52) & $49.56 \pm 3.30(40-55)$ & $49.97 \pm 2.11(45.5 \pm 56)$ & 0.777 \\
\hline & Gestational age, weeks & $39.52 \pm 2.69(38-40)$ & $36.62 \pm 2.01(31-39)$ & $36.0 \pm 3.04(29-40)$ & $<0.001$ \\
\hline & Low birth weight, $\mathrm{kg}$ & $n=0$ & \begin{tabular}{|l|}
$\mathrm{n}=2(8.4 \%)$ \\
$2.220 \pm 0.226$ \\
$(2.060-2.380)$
\end{tabular} & $n=0$ & --- \\
\hline & Normal birth weight, $\mathrm{kg}$ & \begin{tabular}{|l|}
$\mathrm{n}=36(100 \%)$ \\
$3.440 \pm 0.250$ \\
$(3.000-3.985)$
\end{tabular} & \begin{tabular}{|l}
$\mathrm{n}=17(70.8 \%)$ \\
$2.971 \pm 0.525$ \\
$(1.720-3.700)$
\end{tabular} & \begin{tabular}{|l|}
$n=12(66.7 \%)$ \\
$2.977 \pm 0.367$ \\
$(2.380-3.540)$
\end{tabular} & $<0.001$ \\
\hline & High birth weight, $\mathrm{kg}$ & $n=0$ & \begin{tabular}{|l|}
$\mathrm{n}=5(20.8 \%)$ \\
$4.020 \pm 0.412$ \\
$(3.550-4.630)$
\end{tabular} & \begin{tabular}{|l|}
$\mathrm{n}=6(33.3 \%)$ \\
$3.851 \pm 0.194$ \\
$(3.600-4.060)$ \\
\end{tabular} & 0.394 \\
\hline \multirow{5}{*}{ 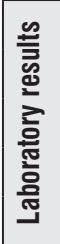 } & Maternal total ghrelin levels, $\mathrm{pg} / \mathrm{mL}^{*}$ & $438.5(350-534.5)$ & $273(110-523.8)$ & 239.2 (127.5-359.9) & $<0.001$ \\
\hline & Neonatal total ghrelin levels, $\mathrm{pg} / \mathrm{mL}^{*}$ & $888.9(558.5-1,244.4)$ & $872.1(637-1,198.7)$ & $831.8(733.2-1,005.4)$ & 0.406 \\
\hline & Maternal proinsulin levels, pMol/L* & $16.8(11.8-21.1)$ & $13.5(9-38.3)$ & $10.9(7.7-15.9)$ & 0.055 \\
\hline & Neonatal proinsulin levels, pMol/L* & $20.1(12.7-32.8)$ & $72.8(22.9-358.2)$ & $32.7(18.8-334.4)$ & $<0.001$ \\
\hline & Maternal HbA1c, \% & $5.5 \pm 0.20(5-6.2)$ & $6.4 \pm 1.6(3.9-10.6)$ & $6.3 \pm 1.3(4.3-9.2)$ & 0.031 \\
\hline
\end{tabular}

Table 2. Total ghrelin and proinsulin levels in the mothers and infants according to glycated hemoglobin levels

\begin{tabular}{|c|c|c|c|c|c|}
\hline & \multirow{2}{*}{$\begin{array}{l}\text { No diabetes } \\
n=36\end{array}$} & \multicolumn{2}{|l|}{ Diabetes } & \multirow{2}{*}{\begin{tabular}{|l|}
${ }^{*} \mathrm{p}$-value \\
All three groups
\end{tabular}} & \multirow{2}{*}{\begin{tabular}{|l} 
tp-value \\
$\geq 6.5 \%$ vs. \\
$<6.5 \%$
\end{tabular}} \\
\hline & & $\begin{array}{l}\text { HbA1c }<6.5 \% \\
n=23\end{array}$ & $\begin{array}{l}H b A 1 c \geq 6.5 \% \\
n=19\end{array}$ & & \\
\hline Maternal total ghrelin, $\mathrm{pg} / \mathrm{mL}$ & $438.5(350-534.5)$ & $247.4(44.7-403.6)$ & $264.39(186.3-531.6)$ & 0.013 & $0.010^{\S}$ \\
\hline Neonatal total ghrelin, $\mathrm{pg} / \mathrm{mL}$ & $888.9(558.5-1,244.4)$ & $918.1(639.6-1,176.1)$ & $791.7(667.0-1,019.6)$ & 0.635 & $0.760^{\S}$ \\
\hline Maternal proinsulin, $\mathrm{pMol} / \mathrm{L}$ & $16.8(11.8-21.1)$ & $11.3(8.9-18.9)$ & $14.4(5.7-23.7)$ & $0.055^{\dagger}$ & $0.076^{* *}$ \\
\hline Neonatal proinsulin, $\mathrm{pMol} / \mathrm{L}$ & $20.1(12.7-32.8)$ & $36.1(22.4-380.3)$ & $49.7(14.4-315.3)$ & $<0.001^{\dagger}$ & $<0.001^{* *}$ \\
\hline
\end{tabular}


Gómez-Díaz RA et al.

Glycemic Control, Ghrelin and Proinsulin

\begin{tabular}{|c|c|c|c|c|c|c|}
\hline & & $n(\%)$ & $\begin{array}{l}\text { Pre-term births } \\
\text { median (IQR) }\end{array}$ & $n(\%)$ & $\begin{array}{l}\text { Term births } \\
\text { median (IQR) }\end{array}$ & $p$-value \\
\hline \multirow{4}{*}{ 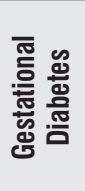 } & Maternal total ghrelin, $\mathrm{pg} / \mathrm{mL}$ & $12(50)$ & $450.8(268.7-600.1)$ & $12(50)$ & $127.9(26.5-367.8)$ & $0.031 *$ \\
\hline & Neonatal total ghrelin, $\mathrm{pg} / \mathrm{mL}$ & $12(50)$ & $732.1(538.9-1,320.9)$ & $12(50)$ & $983.0(678.5-1,198.7)$ & $0.646^{*}$ \\
\hline & Maternal proinsulin, pMol/L & $12(50)$ & $18.9(8.9-55.5)$ & $12(50)$ & $13.5(9.2-19.9)$ & $0.630^{* *}$ \\
\hline & Neonatal proinsulin, pMol/L & $12(50)$ & $29.2(16.4-113.5)$ & $12(50)$ & $248.7(42.5-525.5)$ & $0.033^{* *}$ \\
\hline \multirow{4}{*}{ 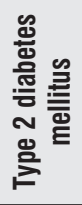 } & Maternal total ghrelin, $\mathrm{pg} / \mathrm{mL}$ & $7(39)$ & $247.3(202.1-304.2)$ & $11(61)$ & $203.2(45.3-398.2)$ & $0.520^{*}$ \\
\hline & Neonatal total ghrelin, $\mathrm{pg} / \mathrm{mL}$ & $7(39)$ & $792.0(700.6-918.1)$ & $11(61)$ & $909.5(744.1-1,019.6)$ & $0.367^{*}$ \\
\hline & Maternal proinsulin, $\mathrm{pMol} / \mathrm{L}$ & $7(39)$ & $7.7(5.6-10.6)$ & $11(61)$ & $15.4(9.2-20)$ & $0.027^{* *}$ \\
\hline & Neonatal proinsulin, pMol/L & $7(39)$ & $23.8(12.9-36.1)$ & $11(61)$ & $87.0(20.2-395.4)$ & $0.328^{* *}$ \\
\hline \multirow{4}{*}{ 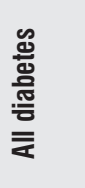 } & Maternal total ghrelin, $\mathrm{pg} / \mathrm{mL}$ & $19(45)$ & $304.2(246.5-531.6)$ & $23(55)$ & 163.6 (33.7-398.2) & $0.019 *$ \\
\hline & Neonatal total ghrelin, $\mathrm{pg} / \mathrm{mL}$ & $19(45)$ & $791.7(563.3-1,036.5)$ & $23(55)$ & $925.3(713.3-1,084.4)$ & $0.505^{*}$ \\
\hline & Maternal proinsulin, pMol/L & $19(45)$ & $9.9(7.6-33.7)$ & $23(55)$ & $15.4(9.2-20.0)$ & $0.536^{* *}$ \\
\hline & Neonatal proinsulin, pMol/L & $19(45)$ & $28.3(14.4-64.7)$ & $23(55)$ & $126.4(22.4-405.7)$ & $0.029 * *$ \\
\hline
\end{tabular}

\section{Discussion}

The findings of this study support the concept that ghrelin affects the adaptive response to caloric imbalance. In this context, diabetic pregnancy can involve a positive or negative caloric balance, although women with T2DM typically have a caloric surplus. Our data show that women with gestational or T2DM had significantly lower plasma ghrelin concentrations at term compared to the non-diabetic controls. However, this difference was not observed for women with pre-term neonates, which may indicate that this is an obstetric complication that is caused by ambient stress and/or caloric deficiency. This interaction may explain the partial correction of low ghrelin plasma concentrations in women with pre-term birth compared to women with diabetes. Our results also suggest that ghrelin participates in the adaptation to the caloric imbalance of diabetic pregnancy and may play a similar role in pregnancy-related complications. Few reports have evaluated plasma ghrelin concentrations in women with diabetes and their offspring, although Kos et al (23) found lower plasma ghrelin levels at the end of pregnancy in women with T1DM. However, this finding was not replicated by Hehir et al (24), and Lappas et al (25) reported lower plasma ghrelin concentrations in women with GD, with persistence of this abnormality at 12 weeks postpartum predicting incident maternal diabetes. Aydin et al (26) found transitory low ghrelin levels in women with GD, although the levels normalized at 2 weeks post-partum. The same trend was observed in pregnant women with pre-gestational T2DM, although their ghrelin concentrations remained low compared to the control group. Our results extend the available evidence and indicate that maternal ghrelin concentrations decrease during pregnancy in women with type 2 or GD.
The low ghrelin concentrations during diabetic pregnancy may be related to maternal or placental factors. Insulin resistance is a common feature of T2DM that is exacerbated during pregnancy and is usually associated with decreased ghrelin secretion (27). The placenta also plays an important role in maintaining the appropriate circulating levels of maternal ghrelin during the later gestational stages. Therefore, diabetic pregnancy is a cause of endothelial dysfunction and premature placental aging, which may result in abnormal placental ghrelin secretion.

Our observation that pre-term birth partially reverses low ghrelin concentrations in pregnant women with diabetes is relevant, as maternal ghrelin concentrations do not vary significantly during a normal pregnancy (28). Interestingly, high ghrelin concentrations have been detected in the cord blood of pre-term and small-for-gestational-age infants $(5,7)$. One study evaluated children of women with T1DM and reported that cord blood ghrelin concentrations negatively correlated with birth weight and that female infants had higher ghrelin concentrations. We also observed that weightfor-gestational-age negatively correlated with serum ghrelin in at-term neonates, which is similar to a previous report of weight-for-gestational-age being negatively correlated with neonatal serum ghrelin levels (29). However, another study reported that ghrelin levels did not differ between pre-term and at-term neonates (30). Nevertheless, maternal ghrelin at the end of a pregnancy is not correlated with fetal birth weight or placental weight (23), although there are no data regarding maternal serum ghrelin concentrations in pre-term neonates. These data suggest that maternal ghrelin may help control fetal growth, and ghrelin may be needed for fetal adaptation to abnormal uterine conditions, such as hyperglycemia (31). 
Additionally, abnormal ghrelin levels in the newborn may have long-term consequences in the regulation of appetite and weight (32).

Reports have consistently indicated that diabetes in pregnant women increases neonatal proinsulin concentrations, regardless of birth weight. For example, the fetal pancreas would respond to maternal hyperglycemia by increasing insulin production and subsequently cause beta cell hyperplasia in the islets of Langerhans $(33,34)$. Although the effect of maternal diabetes on the conversion of proinsulin to insulin in the fetus is not known, our findings confirm reports which indicate that proinsulin levels are higher in neonates born to diabetic mothers (35). Proinsulin levels may also be a risk marker for the development of diabetes, metabolic syndrome, arterial hypertension, dyslipidemia, and other metabolic diseases (36).

The present study has several limitations. First, the sample size was small, so the conclusions may not be definitive. Secondly, approximately half of the mothers were receiving insulin, and this treatment heterogeneity may be a confounding factor. We also did not have the means, in this paper, to evaluate the differences in age and BMI of the subjects, which might be considered a confounding factor, as suggested by Tschop et al (37). However, both age and BMI were considered in the logistic regression. Also, we did not collect data regarding acylated ghrelin (the active form), although both acylated and unacylated ghrelin levels are altered by diabetes $(38,39)$. Finally, we cannot compare ghrelin levels with those in other studies, due to the heterogeneity of measurement methodology.

In conclusion, ghrelin levels were lower in pregnant women with diabetes, although pre-term birth appeared to reverse this trend in GD. The proinsulin concentrations in pregnant women with diabetes were generally low, and this was particularly true among pregnant women with T2DM and pre-term birth (vs. at-term birth). Finally, among pregnant women with diabetes, proinsulin and ghrelin concentrations were lower in women with $\mathrm{HbA} 1 \mathrm{c}$ of $<6.5 \%$. These data appear to indicate that ghrelin and proinsulin concentrations in pregnant women and their offspring depend on the type of maternal diabetes, gestational age at birth, and the degree of maternal glycemic control.

\section{Acknowledgments}

The authors thank Ms. Susan Drier for helping prepare this manuscript, Leonardo Cruz-Reynoso and Luisa Sánchez-García for patient recruitment, Ms. Sandra Campos for taking the blood samples, and Mr. Ricardo Cesar Saldaña-Espinoza for helping with the statistical analysis.

\section{Ethics}

Ethics Committee Approval: The study was approved by the Ethics and Research Committee of the Mexican Social Security Institute, complied with the tenets of the Declaration of Helsinki, Informed Consent: All participants provided written informed consent.
Peer-review: Externally peer-reviewed.

\section{Authorship Contributions}

Concept: Rita Angélica Gómez-Díaz, Design: Rita Angélica Gómez-Díaz, Data Collection or Processing: Monica P. GómezMedina, Eleazar Ramírez-Soriano, Lucio López-Robles, Analysis or Interpretation: Renata Saucedo, Adan Valladares-Salgado, Literature Search: Arturo Zarate, Adan Valladares-Salgado, Writing: Rita Angélica Gómez-Díaz, Carlos A. Aguilar-Salinas, Niels H. Wacher.

Financial Disclosure: The authors thank CONACYT for funding (grant: SALUD-2010-01-142314)

\section{References}

1. Gualillo O, Caminos J, Blanco M, Garcia-Caballero T, Kojima M, Kangawa K, Dieguez C, Casanueva F. Ghrelin, a novel placental-derived hormone. Endocrinology 2001;142:788-794.

2. Theander-Carrillo $C$, Wiedmer P, Cettour-Rose P, Nogueiras R, PerezTilve D, Pfluger P, Castaneda TR, Muzzin P, Schurmann A, Szanto I, Tschop MH, Rohner-Jeanrenaud F. Ghrelin action in the brain controls adipocyte metabolism. J Clin Invest 2006;116:1983-1993. Epub 2006 Jun 8

3. Soriano-Guillen L, Barrios V, Argente J. [Physiopathological features and diagnostic utility of ghrelin protein in pediatrics]. An Pediatr (Barc) 2004;61:5-7.

4. Tham E, Liu J, Innis S, Thompson D, Gaylinn BD, Bogarin R, Haim A, Thorner MO, Chanoine JP. Acylated ghrelin concentrations are markedly decreased during pregnancy in mothers with and without gestational diabetes: relationship with cholinesterase. Am J Physiol Endocrinol Metab 2009;296:E1093-1100. Epub 2009 Feb 24

5. Yokota I, Kitamura S, Hosoda H, Kotani Y, Kangawa K. Concentration of the n-octanoylated active form of ghrelin in fetal and neonatal circulation. Endocr J 2005;52:271-276

6. Prado $C L$, Pugh-Bernard $A E$, Elghazi L, Sosa-Pineda $B$, Sussel $L$. Ghrelin cells replace insulin-producing beta cells in two mouse models of pancreas development. Proc Natl Acad Sci U S A 2004;101:29242929. Epub 2004 Feb 17

7. Kitamura S, Yokota I, Hosoda H, Kotani Y, Matsuda J, Naito E, Ito M, Kangawa K, Kuroda Y. Ghrelin concentration in cord and neonatal blood: relation to fetal growth and energy balance. J Clin Endocrinol Metab 2003;88:5473-5477.

8. Luque EM, Torres PJ, de Loredo N, Vincenti LM, Stutz G, Santillan ME, Ruiz RD, de Cuneo MF, Martini AC. Role of ghrelin in fertilization, early embryo development, and implantation periods. Reproduction 2014;148:159-167. Epub 2014 May 12

9. Fuglsang J, Sandager P, Moller N, Fisker S, Frystyk J, Ovesen P. Peripartum maternal and foetal ghrelin, growth hormones, IGFs and insulin interrelations. Clin Endocrinol (Oxf) 2006;64:502-509.

10. Vestergaard ET, Moller N, Jorgensen JO. Acute peripheral tissue effects of ghrelin on interstitial levels of glucose, glycerol, and lactate: a microdialysis study in healthy human subjects. Am J Physiol Endocrinol Metab 2013;304:E1273-1280. Epub 2013 Apr 16

11. Hernandez-Sanchez C, Mansilla A, de la Rosa EJ, Pollerberg GE, Martinez-Salas E, de Pablo F. Upstream AUGs in embryonic proinsulin mRNA control its low translation level. EMBO J 2003;22:5582-5592.

12. Bavenholm P, Proudler A, Tornvall P, Godsland I, Landou C, de Faire $\mathrm{U}$, Hamsten A. Insulin, intact and split proinsulin, and coronary artery disease in young men. Circulation 1995;92:1422-1429. 
Gómez-Díaz RA et al.

Glycemic Control, Ghrelin and Proinsulin

13. Robbins DC, Tager HS, Rubenstein AH. Biologic and clinical importance of proinsulin. N Engl J Med 1984;310:1165-1175.

14. Hernandez-Sanchez C, Bartulos O, de Pablo F. Proinsulin: much more than a hormone precursor in development. Rev Endocr Metab Disord 2005;6:211-216.

15. Loeken MR. Current perspectives on the causes of neural tube defects resulting from diabetic pregnancy. Am J Med Genet C Semin Med Genet 2005;135C:77-87.

16. Nickisch S, Kratzsch J, Gebauer C, Waldeyer T, Stepan H, Kiess W. Glucose tolerance in women $24 \mathrm{~h}$ postpartum is related to blood pressure, anthropometric data, and adipokine serum levels. Hypertens Pregnancy 2012;31:228-239. Epub 2012 Mar 1

17. Hodish I, Absood A, Liu L, Liu M, Haataja L, Larkin D, Al-Khafaji A, Zaki A, Arvan P. In vivo misfolding of proinsulin below the threshold of frank diabetes. Diabetes 2011;60:2092-2101. Epub 2011 Jun 15

18. Sandovici I, Hoelle K, Angiolini E, Constancia M. Placental adaptations to the maternal-fetal environment: implications for fetal growth and developmental programming. Reprod Biomed Online 2012;25:68-89. Epub 2012 Apr 5

19. American Diabetes A. Erratum. Classification and diagnosis of diabetes. Sec. 2. In Standards of Medical Care in Diabetes-2016. Diabetes Care 2016;39(Suppl. 1):S13-S22. Diabetes Care 2016;39:1653.

20. Capurro H, Konichezky S, Fonseca D, Caldeyro-Barcia R. A simplified method for diagnosis of gestational age in the newborn infant. J Pediatr 1978;93:120-122.

21. Lubchenco LO, Hansman C, Dressler M, Boyd E. Intrauterine Growth as Estimated from Liveborn Birth-Weight Data at 24 to 42 Weeks of Gestation. Pediatrics 1963;32:793-800.

22. Group HSCR, Metzger BE, Lowe LP, Dyer AR, Trimble ER, Chaovarindr U, Coustan DR, Hadden DR, McCance DR, Hod M, Mclntyre HD, Oats JJ, Persson B, Rogers MS, Sacks DA. Hyperglycemia and adverse pregnancy outcomes. N Engl J Med 2008;358:1991-2002.

23. Kos K, Syn WK, Lewandowski KC, Bennett J, Nwokolo CU, O'Hare JP, Randeva H. Comparison of maternal ghrelin and leptin in healthy mothers and mothers with Type 1 diabetes. Diabet Med 2008;25:1400-1405.

24. Hehir MP, Laursen $H$, Higgins MF, Brennan DJ, O'Connor DP, McAuliffe FM. Ghrelin concentrations in maternal and cord blood of type 1 diabetic and non-diabetic pregnancies at term. Endocrine 2013:43:233-235. Epub 2012 Jun 28

25. Lappas M, Jinks D, Ugoni A, Louizos CC, Permezel M, Georgiou HM. Post-partum plasma C-peptide and ghrelin concentrations are predictive of type 2 diabetes in women with previous gestational diabetes mellitus. J Diabetes 2015;7:506-511. Epub 2015 Mar 4

26. Aydin S, Geckil H, Karatas F, Donder E, Kumru S, Kavak EC, Colak R, Ozkan Y, Sahin I. Milk and blood ghrelin level in diabetics. Nutrition 2007;23:807-811.
27. Poykko SM, Kellokoski E, Horkko S, Kauma H, Kesaniemi YA, Ukkola O. Low plasma ghrelin is associated with insulin resistance, hypertension, and the prevalence of type 2 diabetes. Diabetes 2003;52:2546-2553.

28. Saylan F, Koken G, Cosar E, Koken T, Saylan A, Arioz DT, Sahin F, Koken R, Yilmazer M. Maternal and fetal leptin and ghrelin levels: relationship with fetal growth. Arch Gynecol Obstet 2011;284:327-329. Epub 2010 Sep 10

29. Ng PC, Lee CH, Lam CW, Wong E, Chan IH, Fok TF. Plasma ghrelin and resistin concentrations are suppressed in infants of insulindependent diabetic mothers. J Clin Endocrinol Metab 2004;89:55635568.

30. Soriano-Guillen L, Barrios V, Chowen JA, Sanchez I, Vila S, Quero J, Argente J. Ghrelin levels from fetal life through early adulthood: relationship with endocrine and metabolic and anthropometric measures. J Pediatr 2004;144:30-35.

31. Repaci A, Gambineri A, Pagotto U, Pasquali R. Ghrelin and reproductive disorders. Mol Cell Endocrinol 2011;340:70-79. Epub 2011 Mar 29

32. Ueno $H$, Nakazato M. Mechanistic relationship between the vagal afferent pathway, central nervous system and peripheral organs in appetite regulation. J Diabetes Investig 2016 doi: 10.1111/jdi.12492. Epub Epub ahead of print.

33. Garcia Carrapato MR. The offspring of gestational diabetes. J Perinat Med 2003;31:5-11.

34. Bush NC, Chandler-Laney PC, Rouse DJ, Granger WM, Oster RA, Gower BA. Higher maternal gestational glucose concentration is associated with lower offspring insulin sensitivity and altered beta-cell function. J Clin Endocrinol Metab 2011;96:E803-809. Epub 2011 Feb 23

35. Lindsay RS, Walker JD, Halsall I, Hales CN, Calder AA, Hamilton BA, Johnstone FD, Scottish Multicentre Study of Diabetes in P. Insulin and insulin propeptides at birth in offspring of diabetic mothers. J Clin Endocrinol Metab 2003;88:1664-1671.

36. Haffner SM, Mykkanen L, Stern MP, Valdez RA, Heisserman JA, Bowsher RR. Relationship of proinsulin and insulin to cardiovascular risk factors in nondiabetic subjects. Diabetes 1993;42:1297-1302.

37. Tschop M, Weyer C, Tataranni PA, Devanarayan V, Ravussin E, Heiman ML. Circulating ghrelin levels are decreased in human obesity. Diabetes 2001;50:707-709.

38. Barazzoni $R$, Zanetti $M$, Ferreira $C$, Vinci P, Pirulli A, Mucci $M$, Dore F, Fonda M, Ciocchi B, Cattin L, Guarnieri G. Relationships between desacylated and acylated ghrelin and insulin sensitivity in the metabolic syndrome. J Clin Endocrinol Metab 2007;92:3935-3940. Epub 2007 Jul 24

39. Gibson W, Liu J, Gaylinn B, Thorner MO, Meneilly GS, Babich SL, Thompson D, Chanoine JP. Effects of glucose and insulin on acyl ghrelin and desacyl ghrelin, leptin, and adiponectin in pregnant women with diabetes. Metabolism 2010;59:841-847. Epub 2009 Dec 16 